\title{
The influence of clinical supervision and its potential for enhancing patient safety - Undergraduate nursing students' views
}

\author{
Kirsten Eika Amsrud ${ }^{* 1}$, Anne Lyberg ${ }^{2}$, Elisabeth Severinsson ${ }^{2}$ \\ ${ }^{1}$ Institute of Nursing Science, Faculty of Health Sciences, Buskerud and Vestfold University College, Kongsberg, Norway \\ ${ }^{2}$ Centre for Women's, Family and Child Health, Faculty of Health Sciences, Buskerud and Vestfold University College, \\ Kongsberg, Norway
}

Received: November 28, 2014

Accepted: February 27, 2015

Online Published: April 10, 2015

DOI: $10.5430 /$ jnep.v5n6p87

URL: http://dx.doi.org/10.5430/jnep.v5n6p87

\begin{abstract}
Objective: The clinical learning environment and supervision are crucial for the development of a professional stance and identity as well as for ensuring patient safety. This study aims to investigate the influence of clinical supervision provided to nursing students by nurse facilitators in hospital settings. An additional objective was to report the relationship between clinical supervision and patient safety.

Methods: In this cross-sectional study, the sample consisted of 66 nursing students recruited after their clinical placement during the second year of the bachelor programme. Data were collected by means of questionnaires and analysed using a descriptive and explorative method.

Results: Regarding the impact of clinical supervision, a moderately significant relationship was found between the three factors "Increased patient participation and problem solving", "User involvement in terms of patient integrity" $(r=0.48)$ and "Enabling patient and family member participation" $(r=0.42)$ and the following Effects of Supervision Scale (ESS) factors; "Interpersonal skills" ( $r=0.47)$, "Professional skills" $(r=0.50)$ and "Communication skills" $(r=0.59)$. There was also a moderately significant relationship between the factors "Trust/Rapport" and "Influence of supervision" for the item "Supportive yet challenging relationships" $(r=0.60)$. In addition, there was a strong correlation between the factors "Supervision advice/support issues" and "Influence of supervision" $(r=0.73)$. The former correlated weakly with "User involvement", i.e., maintaining integrity $(r=$ $0.33)$.

Conclusions: The nursing students reported increased awareness and a strong improvement related to interpersonal, professional and communication skills. These findings emphasize the potential of clinical supervision to contribute to personal growth and a caring attitude towards patients, thereby strengthening the development of skills essential for patient safety care. A practical implication of the findings is that nursing students' clinical placement and clinical supervision can be better utilized to achieve the overall aim of nursing education, i.e., ensuring patient safety.
\end{abstract}

Key Words: Clinical nursing education, Nurse facilitators, Nursing students, Patient safety, Supervision

\section{INTRODUCTION}

The overall aim of nursing education is to improve the quality of care, thereby ensuring patient safety. ${ }^{[1]}$ To achieve this goal increased attention must be paid to the quality of nursing education. The nursing study programmes in Europe are guided by European Union directives (2013/155/EU), ${ }^{[2]}$

*Correspondence: Kirsten Eika Amsrud; Email: Kirsten.E.Amsrud@hbv.no; Address: Institute of Nursing Science, Faculty of Health Sciences, Buskerud and Vestfold University College, Kongsberg, Norway.

Published by Sciedu Press 
which in most countries means a 3-year higher education course (180 credits in the European Union Credit Transfer System). According to EU and National Curriculum for Nursing Education in Norway directives, ${ }^{[2,3]}$ half of the education must comprise studies in clinical areas. In view of this fact, the clinical learning environment and the supervisor's impact on the students' learning processes and outcomes are crucial for the development of a professional stance and identity. Some countries such as the UK have national standards for supervisors of nursing students, which include requirements on training, local registration, review and annual updating of qualifications. ${ }^{[4]}$ However, in Norway there are no such nationally agreed standards.

Serious deficiencies in the clinical part of health and social work programmes have recently been identified. ${ }^{[5,6]}$ Several reports highlight lack of quality due to a shortage of resources and frames, random selection of supervisors without reference to supervisory competence requirements, managers who do not provide time for supervision and structures that are too weak for cooperation between the educational institutions and their field of practice. ${ }^{[7,8]}$

The Norwegian Ministry of Education and Research ${ }^{[9]}$ has initiated processes to improve this complex and challenging situation. The Norwegian Association of Higher Education Institutions has been called upon to establish a national project to strengthen the quality and relevance of clinical studies in health and social work programmes. In addition, the Norwegian Nursing Education Network (SUFAL) has formulated national learning outcomes to ensure equal standards in the 23 Universities and University Colleges that provide nursing study programmes. SUFAL has also started to develop an assessment instrument for clinical placement in collaboration with The University of Wollongong, Australia.

The term "supervising" is not universally used in the clinical practice component of nursing education; similar terms such as mentoring, tutoring, preceptoring and facilitating are also employed. ${ }^{[10]}$ Based on a systematic literature review, Jokelainen et al. ${ }^{[11]}$ identified two important themes in supervision models for nursing students in clinical placements; Facilitating students' learning and Strengthening students' professionalism.

There are different definitions of supervision, several of which describe learning through a process of reflection ${ }^{[12-14]}$ based on models ${ }^{[15]}$ and interpersonal support. Supervision can be defined as a pedagogical human development process, where the participants raise questions, explore, explain and systematize care experiences from a perspective that is considered holistic in a professional context. ${ }^{[12]}$ In operational terms, the purpose of supervision in nursing students' clini- cal education is described as maintaining and promoting care standards, practice-focused professional relationships and reflecting on practice with an experienced practitioner. Previous studies on the effects of nursing student supervision provide evidence of increased understanding of patient needs, ${ }^{[16]}$ communication and organisation, ${ }^{[17,18]}$ quality of nursing care and patient relationships, ${ }^{[19]}$ in addition to greater responsibility, ${ }^{[20]}$ development of a professional identity, enhanced decision-making ability and personal growth. ${ }^{[21]}$

The Commission of European Communities ${ }^{[22]}$ defined patient safety as the prevention of unnecessary or potential harm associated with healthcare. Other definitions are related to the dynamic system of healthcare and focus on the interaction of several elements. ${ }^{[23,24]}$ These definitions assume that incidents are the result of ineffective interaction between the actors involved. ${ }^{[25]}$ According to Mitchell, ${ }^{[26]}$ patient safety is often described as preventing harm, thus negative outcomes of care are in focus. Nurses are in a key position to improve the quality of healthcare through patient safety interventions and strategies, thus there is a huge potential for evaluating the impact of nursing care on positive quality indicators. The NMC Code ${ }^{[4]}$ and the Royal College of Nursing Principles of Nursing Practice ${ }^{[27]}$ have identified patient safety as an essential part of nursing care. In light of this fact, it should be borne in mind that nursing care implies meeting patient needs and encountering patients with respect, as failure to do so could constitute harm.

For this reason, nurses need to be prepared for their future professional role by providing them with tools in the form of knowledge, skills and attitudes, thus enabling them to continuously improve the quality and safety of care. ${ }^{[28]}$ Therefore an important question is how the supervision of nursing students in clinical placements can strengthen such a development.

According to Severinsson \& Sand, ${ }^{[21]}$ there is increasing awareness of the value of clinical supervision (CS), which is also supported by previous research. To make full use of the potential of CS it is necessary to focus on learner, faculty and organisational factors. Teaching quality improvement and patient safety to nursing students is a complex and challenging activity that involves environmental, collegial, pedagogical and clinical attributes. ${ }^{[1,29]}$ The present study investigates nursing students' views of their clinical supervision. This is necessary due to the urgent need to transform nursing curricula so that the competencies of new graduates more closely match practice needs as well as quality and safety. ${ }^{[30]}$ Knowledge of the value and potential of CS for enhancing such skills is important in terms of the quality of education and safety care. Therefore, this research focuses on key aspects 
of patient safety that reflect professional competence such as communication, learning, development of a professional stance and identity.

\section{Objectives}

The objective of this study was to investigate the influence of CS provided to nursing students by nurse facilitators in hospital settings. An additional objective was to report the relationship between CS and patient safety.

\section{METHODS}

\subsection{Design}

A descriptive-correlational design was used. ${ }^{[31]}$

\subsection{Sample and data collection}

All nursing students $(n=76)$ in the second year of the bachelor programme were identified and invited to participate in the study by their nurse teachers during one of the theoretical lessons in June 2012. The nursing students had their clinical nursing education placement (medical and surgical care) at a University Hospital in eastern Norway. The questionnaires were placed in an envelope, distributed to those who agreed to participate and returned to one of the authors. The sample consisted of 66 nursing students (response rate 86.8\%) in the second year of the bachelor programme.

\subsection{Research questionnaire}

The nursing students' views of the effects of CS were assessed by means of a questionnaire that included demographic items, the Manchester Clinical Supervision Scale (MCSS), ${ }^{[32]}$ the Effects of Supervision Scale (ESS) ${ }^{[12]}$ and the Focus on Empowerment Scale (FEES). ${ }^{[21]}$ The MCSS scale consists of 36 items divided into six factors; Trust/Rapport; Supervisor advice/support; Improved care/skills; Finding time; Personal issues and Reflection. The theoretical components of these factors from Proctor's model ${ }^{[33]}$ are labelled: Normative, i.e., organisational responsibility and quality control, Formative, i.e., development of skills and knowledge, and Restorative, i.e., personal wellbeing. The existing sub-scale labels were used. ${ }^{[32]}$ The instrument was translated into Norwegian, ${ }^{[21]}$ after which its hypothezised seven-factor structural model was tested and verified. ${ }^{[34]}$ The participants used a five-point Likert scale ranging from 1 (strongly disagree) to 5 (strongly agree) to respond to items such as "My supervisor gives me support and encouragement and Clinical supervision sessions facilitate reflective practice".

The ESS scale ${ }^{[12]}$ (27 items) uses a 4-point response scale ranging from 1 (strongly disagree) to 4 (strongly agree) and comprises three sub-scales (Interprofessional skills, Professional skills and Communication skills) that measure what the nursing students have learnt in the supervision process. Finally, the FESS scale, a 24-item instrument, measures nursing documentation, patients' and family members' involvement in care as well as nursing students' perceptions of the influence of supervision with scores from 1 (strongly disagree) to 4 (strongly agree). Examples of statements pertaining to documentation are: "I use all parts of the problemsolving process when I document" and "I am educated in how to develop the nursing process documentation". All items in the FESS scale have been published elsewhere. ${ }^{[21]}$

\subsection{Data analysis}

A computerized descriptive analysis of the responses was made using the Statistical Package for the Social Sciences (SPSS) version 20.0 for Windows. ${ }^{[35]}$ Descriptive statistics and reliability were examined for all scale variables. Factor analysis with varimax rotation was employed to reduce the number of underlying items in the descriptive and inferential analyses. Items with a negative loading were reversed. The analysis process continued by testing internal consistency by means of Cronbach's alpha, while the Spearman rank correlation coefficient was used to calculate correlations between factors. ${ }^{[36]} \mathrm{A} p$-value of $<.05$ was deemed statistically significant.

\subsection{Ethical considerations}

Ethical approval was granted by the principal tutor and the dean of the Faculty of Buskerud and Vestfold University College. Permission to use the instruments was obtained from the copyright holders and for the MCSS from Dr. J. Winstanley, Australia. The nursing students who participated were provided with verbal and written information about the study and signed their informed consent. None of the nursing teachers who distributed the questionnaires were involved in the individual assessment or examination in this part of the study programme. The questionnaires were coded with numbers in order to ensure confidentiality. The Helsinki declaration guidelines ${ }^{[37]}$ were adhered to.

\section{RESULTS}

\subsection{Demographic characteristics of the participants, fre- quency of sessions and supervision model}

The sample consisted of the 66 nursing students who completed the survey, 27 (41.5\%) of whom were based in the medical department and $38(58.5 \%)$ in the surgical department (one internal missing). Their mean age was 24 years $(22-30)$ and $61(93.8 \%)$ were female. $38(57.6 \%)$ had experience of other work prior to the nursing programme. Of the clinical nurse supervisors, 59 (89.4\%) were female, 14 $(21.5 \%)$ had taken part in a course for supervisors, while 11 had not and $40(61.5 \%)$ did not provide any information. The 
frequency of the nursing students' contact with their supervisor was: daily $(n=31)(47.7 \%)$, weekly $(n=26)(40 \%)$, every second week $(n=6)(9.2 \%)$ and once a month $(n=2)$ $(3.1 \%)$. There were three supervision models; work-related patient situations $(n=23)$, a separate room at the workplace $(n=5)$ and a combination of both $(n=38)$. Most of the supervision was individual $(\mathrm{n}=39)$, while 4 nursing students attended group sessions and 23 a combination of individual and group supervision. Only 15 of the students had attended supervision before the programme, while the rest $(77.3 \%)$ had not.

A majority of the students $(n=26)(40 \%)$ had attended su- pervision sessions that lasted for 15-30 minutes, 14 students $(21.5 \%)<15$ minutes and 25 students $(38.5 \%)$ 30-60 minutes (one internal missing). The supervision was reported as adequate by 32 and inadequate by 34 students.

\subsection{Learning and professional development as a result of clinical supervision}

A 3-factor grouping was chosen for the questions related to what the nursing students had learnt in CS (see Table 1). This structure explained $63.05 \%$ of the variance. The overall alpha coefficient for the nursing students' perceptions of their increased awareness of "Interprofessional skills", "Professional skills" and "Communication skills" was 0.96.

Table 1. Factor analysis and Cronbach's alpha coefficients of the nursing students' $(\mathrm{N}=66)$ views on what they had learnt in clinical supervision

\begin{tabular}{|c|c|c|}
\hline Scales and items & Factor loading & Cronbach's alpha \\
\hline \multicolumn{2}{|l|}{ F1 Increased awareness of interpersonal skills } & \multirow{12}{*}{0.94} \\
\hline Q3 I can deal with difficult caring situations & 0.79 & \\
\hline Q2 I can better "face" the patient & 0.75 & \\
\hline Q1 I have gained insight & 0.75 & \\
\hline Q24 I have a professional identity & 0.68 & \\
\hline Q16 I find it easier to ask the patient questions & 0.66 & \\
\hline Q25 I have developed an ethical stance & 0.64 & \\
\hline Q15 I can listen more deeply & 0.62 & \\
\hline Q21 I feel a greater responsibility for activities on the ward & 0.58 & \\
\hline Q9 I can see patients' needs more clearly & 0.58 & \\
\hline Q6 I have more options in terms of how to act & 0.57 & \\
\hline Q11 I can plan more easily together with the patient & 0.55 & \\
\hline \multicolumn{2}{|l|}{ F2 Increased awareness of professional skills } & \multirow{12}{*}{0.92} \\
\hline Q13 I can explain what I mean & 0.80 & \\
\hline Q7 I inform others about things that do not work properly & 0.72 & \\
\hline Q12 I can help the patient to describe her/his feelings & 0.67 & \\
\hline Q17 I can more easily request advice from colleagues & 0.66 & \\
\hline Q4 I dare to assume responsibility & 0.66 & \\
\hline Q20 I have learnt to better understand others & 0.59 & \\
\hline Q10 It is easier for me to talk about feelings & 0.58 & \\
\hline Q5 I can support others & 0.58 & \\
\hline Q8 I cooperate better with other specialists & 0.56 & \\
\hline Q14 I can describe the patient's situation & 0.54 & \\
\hline Q22 I experience job satisfaction & 0.46 & \\
\hline \multicolumn{2}{|l|}{ F3 Increased awareness of communication skills } & \multirow{4}{*}{0.80} \\
\hline Q19 I am aware of what I want to achieve & 0.86 & \\
\hline Q23 I realize when I need help from others & 0.76 & \\
\hline Q18 I have learnt about occupational boundaries & 0.59 & \\
\hline
\end{tabular}

Note. Eigenvalues after rotation F1 = 6.45, F2 = 5.65, F3 = 3.67; Explained variance (expressed in per cent) 25.81, F2 = 22.61, F3 = 14.63; Cumulative (expressed in per cent) F1 $=25.81, \mathrm{~F} 2=48.42$, F3 $=63.05$. Cronbach's alpha total $=0.96$. 
3.3 Correlation analyses of documentation, user involvement and the influence of supervision

Intercorrelations between the study variables are presented in Table 2. Several significant associations between the factors on the FESS scale: "Documentation", "User involvement" and the "Influence of supervision" and factors on the ESS scale ("Interpersonal skills", "Professional skills" and "Communication skills") were revealed. There was a moderately significant positive correlation between the three factors "Increased patient participation and problem-solving", "User involvement in terms of preserving patients' integrity" ( $r=$ 0.48 ) and "Enabling patient and family member participation" $(r=0.42)$ and the ESS scale factors; "Interpersonal skills" ( $r$ $=0.47)$, "Professional skills" $(r=0.50)$ and "Communication skills" ( $r=0.59)$. In terms of "Increased communication and documentation skills" the variables correlated with "User involvement", "Preserving integrity" $(r=0.34)$ and "Enabling patient and family member participation" $(r=0.40)$ and the EES factors "Interpersonal skills" $(r=0.70)$, "Professional skills" $(r=0.59)$ and "Communication skills" $(r=0.61)$. "Influence of supervision" was not significantly correlated with "User involvement" although moderately significant correlations were found between "Influence of supervision" and the factors "Interpersonal skills" $(r=0.51)$, "Professional skills" $(r=0.42)$ and "Communication skills" $(r=0.51)$. The factor "Preparatory for and confirming professional relationships" was not significantly correlated with "User involvement", although "Influence of supervision" correlated moderately with "Interpersonal skills" $(r=0.42)$, "Professional skills" $(r$ $=0.42$ ).

Table 2. Spearman correlation between factors of user involvement, documentation skills and the influence of supervision

\begin{tabular}{|c|c|c|c|c|}
\hline \multirow[b]{2}{*}{ Documentation } & \multicolumn{4}{|c|}{ Influence of supervision } \\
\hline & $\begin{array}{l}\text { Increased patient } \\
\text { participation } \\
\text { and problem solving }\end{array}$ & $\begin{array}{l}\text { Increased } \\
\text { communication and } \\
\text { documentation skills }\end{array}$ & $\begin{array}{l}\text { Supportive yet } \\
\text { challenging } \\
\text { relationship }\end{array}$ & $\begin{array}{l}\text { Preparatory and } \\
\text { confirming professional } \\
\text { relationship }\end{array}$ \\
\hline \multicolumn{5}{|l|}{ User involvement } \\
\hline Preserving integrity & $.478 * * *$ & $.342 * *$ & .198 & .118 \\
\hline $\begin{array}{l}\text { Enabling patient and family } \\
\text { member participation EES }\end{array}$ & $.424 * * *$ & $.396 * * *$ & .162 & .084 \\
\hline Interpersonal skills & $.473 * * *$ & $.698 * * *$ & $.508 * * *$ & $.422 * * *$ \\
\hline Professional skills & $.503 * * *$ & $.593 * * *$ & $.424 * * *$ & $.424 * * *$ \\
\hline Communication skills & $.588 * * *$ & $.606 * * *$ & $.506 * * *$ & $.315^{* *}$ \\
\hline
\end{tabular}

$* P<.05 ; * * P<.01 ; * * * P<.001$.

\subsection{Correlation analysis of the factors in the three scales}

There was a moderately significant relationship between the factors "Trust/Rapport" and "Influence of supervision" in relation to the item "Supportive yet challenging relationships" $(r=0.60)$. A strong correlation was found between the factors "Supervision advice/support issues" and "Influence of supervision" ( $r=0.73$ ) (see Table 3). The former correlated weakly with "User involvement" i.e., preserving integrity $(r=0.33)$, "Enabling patient and family member participation" $(r=0.37)$ and moderately with "Increased communication and documentation skills" $(r=0.50)$; "Preparatory and confirming professional relationship" $(r=0.52)$; "Interpersonal skills" ( $r=0.57)$; "Professional skills" $(r=0.50)$ and "Communication skills" $(r=0.52)$. The factor "Improved care/skills" indicated the extent to which nursing students considered that CS enhanced their delivery of care and correlated moderately with "Increased communication and documentation skills" $(r=0.55)$, "Interpersonal skills" $(r=0.45)$ and "Professional skills" $(r=0.41)$. A weak correlation was found between "Improved care/skills" $(r=0.36)$ and "Supportive yet challenging relationships" $(r=0.36)$. "Finding time" correlated weakly with "Increased patient participation" $(r=0.26)$ and "Preparing for and confirming professional relationships" $(r=0.30)$ and moderately with "Supportive yet challenging relationships" $(r=0.41)$.

The factor "Reflection" correlated moderately with "Enabling patient and family member participation" $(r=0.48)$, "Increased communication and documentation skills" $(r=$ $0.40)$; "Interpersonal skills" $(r=0.48)$ and "Professional skills" $(r=0.44)$. Weak correlations were found between "Increased patient participation" ( $r=0.39)$, "Communication skills" $(r=0.34)$ and "Preserving integrity" $(r=0.29)$.

No correlations were found between the two MCSS factors "Importance of CS" and "Personal issues" and the factors on the FESS and ESS scales.

\section{Discussion}

The objective of this study was to investigate the influence of CS provided to nursing students by nurse facilitators in 
hospital settings. An additional objective was to report the relationship between CS and patient safety. Data were investigated by means of descriptive and explorative factor analysis. Several significant correlations were found between the factors "Documentation", "User involvement" and "Inter- personal skills", "Professional skills" and "Communication skills" (see Tables 2 and 3). The nursing students perceived that CS had provided them with an increased awareness of interpersonal, professional and communication skills.

Table 3. Spearman's correlation between factors

\begin{tabular}{|c|c|c|c|c|c|c|c|}
\hline MCCS & $\begin{array}{l}\text { Trust/ } \\
\text { Rapport Time }\end{array}$ & $\begin{array}{l}\text { Supervisor advice/ } \\
\text { support issues }\end{array}$ & $\begin{array}{l}\text { Improved } \\
\text { care/skills }\end{array}$ & $\begin{array}{l}\text { Importance } \\
\text { value of CS }\end{array}$ & $\begin{array}{l}\text { Finding } \\
\text { time }\end{array}$ & Personal & Reflection \\
\hline \multicolumn{8}{|l|}{ User involvement } \\
\hline Preserving integrity & .138 & $.335^{* *}$ & .128 & .022 & -.215 & -.057 & $.292 *$ \\
\hline $\begin{array}{l}\text { Protecting participation by } \\
\text { patients and family members }\end{array}$ & .158 & $.366^{* *}$ & $.330 * *$ & -.208 & -.070 & .188 & $.480 * * *$ \\
\hline \multicolumn{8}{|l|}{ Documentation } \\
\hline Increased patient participation & .229 & $.395 * * *$ & .132 & -.001 & $-.258 *$ & -.059 & $.249 *$ \\
\hline $\begin{array}{l}\text { Increased communication and } \\
\text { documentation skills }\end{array}$ & .210 & $.500 * * *$ & $.551^{* * *}$ & .041 & -.075 & .141 & $.402 * * *$ \\
\hline \multicolumn{8}{|l|}{ Influence of supervision } \\
\hline $\begin{array}{l}\text { Supportive yet challenging } \\
\text { relationship }\end{array}$ & $.600 * * *$ & $.734 * * *$ & $.356 * *$ & -.213 & $-.408 * * *$ & .142 & .132 \\
\hline $\begin{array}{l}\text { Preparatory and confirming } \\
\text { professional relationship }\end{array}$ & $.353^{* *}$ & $.521 * * *$ & .228 & -.175 & $-.292 *$ & .109 & .024 \\
\hline \multicolumn{8}{|l|}{ EES } \\
\hline Interpersonal skills & .241 & $.570^{* * *}$ & $0.454 * * *$ & -.186 & .119 & .174 & $.479 * * *$ \\
\hline Professional skills & $.338 * * *$ & $.497 * * *$ & $0.413^{* * *}$ & -.038 & -.127 & .234 & $.440 * * *$ \\
\hline Communication skills & $.245^{*}$ & $.454 * * *$ & $0.255^{*}$ & -.126 & -.225 & .066 & $.339 * *$ \\
\hline
\end{tabular}

\subsection{Learning and professional development}

The above mentioned findings (see Tables 1-3) are fairly strong, also when compared with the results reported in a corresponding study in western Norway. ${ }^{[21]}$ However, the supervision was reported as inadequate by more than half of the nursing students $(n=34)$. The apparent contradiction between the nursing students' perception of what they learnt in CS and their understanding of CS as inadequate calls for reflection. Both Dawson et al. ${ }^{[38]}$ and Severinsson \& Sand ${ }^{[21]}$ emphasized the complexity and diversity of CS involving a complex interplay of communication, skills, knowledge and decision making. O'Driscoll et al. ${ }^{[39]}$ highlighted the lack of leadership and responsibility for nursing students' learning in practice. These challenges are well known and documented in the Introduction of the present study. Thus, it is not surprising that the nursing students reported CS as inadequate. However, this contradicts their own perceptions of what they learnt in CS, especially when comparing the factor loadings for all three items (see Table 1). It can be argued that CS has a greater influence in the students' complex and challenging everyday clinical placement than they can identify, recognize or describe. In addition, their understanding of the terms adequate/inadequate in this context might be deficient. Another explanation could be that the students are able to utilize their learning ability in the clinical placement to a greater extent than expected. From this perspective the apparent contradiction between the nursing students' perception of what they learnt in CS and their understanding of CS as inadequate is an important opportunity to optimise the learning outcomes of the clinical placement by emphasising student resources. Bradbury-Jones et al. ${ }^{[40]}$ highlighted the opportunities for strengthening nursing students' progress through the programme, which are hidden in experiences of empowerment related to being valued as a learner, a team member and a person. Research on how to do this is very limited and requires strengthening. ${ }^{[40]}$ Regarding the impact of CS, a moderately significant relationship was found between the three factors "Increased patient participation and problem solving", "User involvement in terms of patient integrity" and "Enabling patient and family member participation" and the factors; "Interpersonal skills", "Professional skills" and "Communication skills" (see Table 2). Both "Documentation" and "User involvement" are essential parts of nursing practice. Dealing with them in a professional way is crucial for patient safety.

\subsection{The relationship between $\mathrm{CS}$ and patient safety}

In the present study the students' growth related to the EES factors seems to be reflected in their cooperation both with the patient and with professionals, most likely their super- 
visors. The correlation between "Increased communication and documentation skills" and "Interpersonal skills" is strong $(r=0.70$, see Table 3$)$. These findings reveal that the students developed increased clinical skills related to "Documentation" and "User involvement" as well as becoming more sensitive to patients' needs, which is in accordance with Holm et al. ${ }^{[15]}$ The latter is of major importance in relation to patient safety. ${ }^{[20]}$ Openness, feedback and communication about errors as well as teamwork within hospital units are reported as aspects that strengthen patient safety culture. ${ }^{[41,42]}$ Thus, nurse facilitators should work towards the establishment of a safety culture not only for patients but also for staff and students in order to integrate knowledge, skills, experiences and research in everyday routines. ${ }^{[20]}$ According to Jerak-Zuideremt, ${ }^{[43]}$ the core dimension of uncertain safety involves shared and distributed knowing and acting. Another dimension of uncertain safety is admitting that one does not know and acknowledging that the diagnosis is unclear.

There was no correlation between "Influence of supervision" and "User involvement" in terms of "Supportive yet challenging relationship" or "Preparatory and confirming professional relationship". This finding corresponds with Severinsson \& Sand's study ${ }^{[21]}$ and can most likely be explained as a lack of capacity to include patients and family members at this level. In addition, it should be questioned whether or not the educational programme provides an adequate basis in this respect.

To summarise, the nursing students in the present study reported increased awareness and a strong improvement related to interpersonal, professional and communication skills (see Table 1). Considering their predominant perception of CS as inadequate, there is a need for further investigation related to their ability to utilize their clinical placement. In addition, this study reveals that CS definitely influences the development of skills important for patient safety care (see Table 2). The links between CS and patient safety are discussed in the literature $^{[38,44,45]}$ and Dawson ${ }^{[38]}$ suggested that the former has some positive impact on the latter. Sullivan et al. ${ }^{[29]}$ highlighted that nurses need to be prepared for their future professional practice with tools in the form of knowledge, skills and attitudes, enabling them to continuously improve the quality and safety of care. In this regard, the factor 'Improved care/skills' in the present study is of special interest (see Table 3), as it indicated the extent to which nursing students considered that CS enhanced their delivery of care. "Improved care/skills" correlated moderately with "Increased communication and documentation skills", "Interpersonal skills" and "Professional skills". A weak correlation was found between "Improved care/skills" and "Supportive yet challenging relationships". The factor "Improved care/skills" concerns the students' perception in relation to the statements "CS makes me a better practitioner", "The quality of patient care would deteriorate without CS" and "I think CS improves the quality of the care I give". In the present study improved care/skills are made visible through "Increased communication and documentation skills", "Interpersonal skills" and "Professional skills". All are skills that contribute to making the patient feel cared for. Utilizing this approach corresponds to Mitchell's (2008) ${ }^{[26]}$ emphasis on the need to evaluate the impact of nursing care on positive quality indicators.

In this study there was also a moderately significant relationship between the factors "Trust/Rapport" and "Influence of supervision" for the item "Supportive yet challenging relationships". This concerns the student's experience of support, encouragement and ability to discuss sensitive issues with the supervisor. In addition, there was a strong correlation between the factors "Supervision advice/support issues" and "Influence of supervision". The former correlated moderately with "User involvement" i.e., protecting/maintaining integrity (see Table 3). These significant correlations emphasized the potential of CS to contribute to personal growth and a caring attitude towards the patients. This corresponds with the focus of Holm Wiebe et al. ${ }^{[46]}$ on confirmation as necessary for enabling learning and professional growth. It should be mentioned that no correlations were found between the two MCSS factors "Importance value/Importance of CS" and "Personal issues" and the factors on the FESS and ESS scales. This can be explained by the possibility that nursing students at this level lack the capacity or ability to reflect on themselves and their own practice.

\subsection{Limitations of the study}

The primary limitation of this study is the small sample size. Other limitations are the fact that $59(89.4 \%)$ of the clinical nurse supervisors were female, that only $14(21.5 \%)$ had taken part in a course for supervisors and that 40 (61.5\%) did not provide any information. All instruments had satisfactory Cronbach alpha values, namely $0.58-0.94 .{ }^{[34]}$ However, it could be argued that data were only collected at a single point in time and the students were from one college. Comparing them with a group of nursing students from another University College would have provided a larger sample. Future research should include studies with a qualitative design. The authors recommend studies on clinical nurse facilitators' professional development and clinical supervision competence.

\section{Conclusions}

The nursing students in the present study reported increased awareness and a strong improvement related to interpersonal, professional and communication skills. These findings em- 
phasize the potential of CS to contribute to personal growth and a caring attitude towards patients, thereby strengthening the development of skills important for patient safety care. Thus, clinical placement in general and CS in particular should be regarded as opportunities to achieve the overall aim of nursing education; namely ensuring patient safety. In addition, it can be questioned whether nursing students' ability to utilize their clinical placement has been underestimated.

\section{ACKNOWLEDGEMENTS}

The authors wish to thank the nursing students and teachers who collected the questionnaires for the time and effort they invested in this study. We would also like to thank Gullvi Nilsson and Monique Federsel for reviewing the English and Vibeke Horstmann for statistical and methodological assistance. This study was funded by the Faculty of Health, Institute of Nursing Science, Centre for Women's, Family \& Child Health, Buskerud \& Vestfold University College, Norway.

\section{CONFLiCTS OF INTEREST Disclosure}

The authors declare that there is no conflict of interest statement.

\section{REFERENCES}

[1] Telle S, Liukka M, Jamookeeah D, et al. What Do Nursing Students Learn About Patient Safety? An Integrative Literature Review. Journal of Nursing Education. 2013; 53(1): 7-13. http: //dx.doi.org/10.3928/01484834-20131209-04

[2] European Union. Directive 2013/55/EU of the European Parliament. Available from: http://eur-lex.europa.eu/LexUriServ/Le xUriServ.do?uri=0J :L : 2013:354:0132:0170:en:PDF

[3] KD. Rammeplan for sykepleierutdanning. ([Guidelines for National Curriculum in Nursing education]). Kunnskapsdepartementet [Ministery of Education and Research]; 2008.

[4] Nursing \& Midwifery Council (NMC). Standards to support learning and assessment in practice. NMC Standards for Mentors, Practice Teachers and Teachers. NMC, London; 2008.

[5] Meld. St. 13 (2011-2012) Melding til Stortinget. Utdanning for velferd. Samspill i praksis. Report to the Storting (White paper); 2012.

[6] UHR Norwegian Association of Higher Education Institutions. Fokus på praksisstudiene i helse - og sosialfagutdanningene. Rapport fra UHRs kartleggingsunders $ø$ kelse av ekstern, veiledet praksis som del av studieforløpet for 115 helse- og sosialfagutdanninger; 2010.

[7] Caspersen J, Kårstein A. Kvalitet i praksis. NIFU (Nordic Institute for Studies in Innovation, Research and Education) Rapport 14. Oppfatninger om kvalitet blant praksisveiledere; 2013.

[8] Kårstein A, Caspersen J. Praksis i helse- og sosialfagutdanningene: En litteraturgjennomgang. NIFU (Nordic Institute for Studies in Innovation, Research and Education) Rapport 16; 2014.

[9] The Norwegian Ministry of Education and research. Prosjekt Kvalitet i praksisstudiene Kortform: Praksisprosjektet. Oppdrag til UHR fra KD, ledd i oppfølgingen av Samspillsmeldingen (Meld St nr 13 (2011-2012) Utdanning for velferd. Samspill i praksis); 2014 Available from: http://www.uhr.no/documents/Praksispros jektet_-_status__september_14.pdf

[10] Andrews M, Chilton F. Student and mentor perceptions of mentoring effectiveness. Nurse Education Today. 2000; 20(7): 555562. PMid:12173259 http://dx.doi.org/10.1054/nedt. 2000 .0464

[11] Jokalainen M, Turunen $\mathrm{H}$, Tossavainen $\mathrm{K}$, et al. A systematic review of mentoring nursing students in clinical placements. Journal of Clinical Nursing. 2011; 20: 2854-2867. PMid:21429055 http://dx.doi.org/10.1111/j.1365-2702.2010.03571.x

[12] Severinsson E. Clinical Nursing Supervision in Health Care. Doctoral dissertation. The Nordic School of Public Health, Göteborg; 1995.
[13] Lyth GM. Clinical supervision: a concept analysis. Advanced Nursing. 2000; 31(3): 722-729.

[14] Ekebergh M, Lepp M, Dahlberg K. Reflective learning with Drama in Nursing Education - a Swedish attempt to overcome the theory praxis gap. Nurse Education Today. 2004; 24(8): 622-628. PMid:15519445 http://dx.doi.org/10.1016/j.nedt.2004.07.011

[15] Butterworth T, Bishop V, Carson J. First steps towards evaluating clinical supervision in nursing and health visiting. Theory, policy and practice development: a review. Journal of Clinical Nursing. 1996; 5: 127-32. PMid:8696597 http://dx.doi.org/10.1111/j.136 5-2702.1996.tb00238.x

[16] Holm A-K, Lantz I, Severinsson E. Nursing students' experiences of the effects of continual process-oriented group supervision. Journal of Nursing Management. 1998; 6: 105-113. PMid:9582784 http://dx.doi.org/10.1046/j.1365-2834.1998.00058.x

[17] Severinsson E, Hallberg IL. Systematic clinical supervision, working milieu and influence over duties: the psychiatric nurse's viewpoint - a pilot study. International Journal of Nursing Studies. 1996; 33(4): 394-406. http://dx.doi.org/10.1016/0020-7489(95 ) 00070-4

[18] Severinsson E. Bridging the gap between theory and practice: a supervision programme for nursing students. Journal of Advanced Nursing. 1997; 27: 1269-1277. http://dx.doi.org/10.1046/j $.1365-2648$. 1998.00644.x

[19] Papastavrou E, Lambrinou E, Tsangari H, et al. Student nurses' experience of learning in the clinical environment. Nurse Education in Practice. 2010; 10: 176-182. PMid:19700368 http://dx.doi.org $/ 10.1016 / j$.nepr.2009.07.003

[20] Hansen SB, Rørtveit K, Testad I, et al. Patient experiences of uncertainty- a synthesis to guide nursing practice. Journal of Nursing Management. 2012; 20(2): 266-277. PMid:22380420 http: //dx.doi.org/10.1111/j.1365-2834.2011.01369.x

[21] Severinsson E, Sand Å. Evaluation of the clinical supervision and professional development of student nurses. Journal of Nursing Management. 2010; 18: 669-677. PMid:20840361 http://dx.doi.o $\mathrm{rg} / 10.1111 / \mathrm{j} .1365-2834.2010 .01146 . \mathrm{x}$

[22] European Union. Improving Patient Safety in the EU. Assessing the expected effects of three policy areas for future action. 2008 Available from: http://www .rand.org/content/dam/rand/pu bs/technical_reports/2008/RAND_TR596.sum.pdf

[23] World Health Organization. World Alliance for Patient Safety. Forward Programme 2008-2009. Available from: http: 
//www.who.int/patientsafety/information_centre/rep orts/Alliance_Forward_Programme_2008.pdf?ua=1

[24] World Health Organization. Patient Safety Research. A guide for developing training programmes; 2012. Available from: http://apps. who.int/iris/bitstream/10665/75359/1/97 89241503440_eng.pdf?ua=1

[25] Wiig S, Lindøe PH. Patient safety in the interface between hospital and risk regulator. Journal of Risk Research. 2009; 12 (3-4): 411-427. http://dx.doi.org/10.1080/13669870902952879

[26] Mitchell P. Defining Patient Safety and Quality Care. In: Hughes RG, editor. Patient Safety and Quality: An Evidence-Based Handbook for Nurses. Agency for Healthcare Research and Quality. Rockville; 2008. 1-5.

[27] Royal College of Nursing (RCN) Guidance for Mentors of Student Nurses and Midwives. A RCN toolkit. Royal College of Nursing. London; 2005.

[28] Sullivan D. Connecting nursing education and practice: A focus on shared goals for quality and safety. Nursing Outlook. 2009; 57: 323-331. PMid:19942033 http://dx.doi.org/10.1016/j.out look.2009.08.004

[29] Wong B, Etchells E, Kuper A, et al. Teaching quality improvement and patient safety to trainees: a systematic review. Academic Medicine. 2010; 85(9): 1425-1439. PMid:20543652 http: //dx.doi.org/10.1097/ACM.0b013e3181e2d0c6

[30] Sherwood G, Drenkard K. Quality and safety curricula in nursing education: Matching practice realities. Nursing Outlook. 2007; 55: 151-155. PMid:17524803 http://dx.doi.org/10.1016/j.out look. 2007.02.004

[31] Polit D, Beck CT. Nursing Research. Appraising Evidence for Nursing Practice. Seventh ed. Philadelphia. Lippincott, Williams \& Williams; 2006

[32] Winstanley J. Manchester Clinical Supervision Scale. Nursing Standard. 2002; 19: 31-32.

[33] Proctor B. Supervision: a co-operative exercise in accountability. In Enabling and Ensuring: Supervision in Practice (Marken M. \& Payn M. eds.). National Bureau and Council for Education and Training in Youth and Community Work. Leicester; 1991.

[34] Severinsson E. Evaluation of Manchester Clinical Supervision Scale - Norwegian and Swedish versions. Journal of Nursing Management. 2012; 20: 81-89. PMid:22229904 http://dx.doi.org/10.1111 /j.1365-2834.2011.01297.x

[35] SPSS. SPSS Inc. LEAD Technologies, Haddonfield, NJ, USA; 2002.
[36] Siegel S, Castellan JN. Nonparametric Statistics for the Behavioral Sciences. Mc Graw-Hill Inc. New York; 1998.

[37] World Medical Association. Declaration of Helsinki, Ethical Principles for Medical Research Involving Human Subjects. Adopted by the 59th WMA General Assembly Seoul; October; 2008. Available from: http: //www. wma.net

[38] Dawson JM. Healthcare Worker and Patient Safety: The Inextricable Link. American Nurse Today. 2013; 8(7).

[39] O'Driscoll MF, Allan HT, Smith PA. Still looking for leadership - Who is responsible for student nurses' learning in practice? Nurse Education Today. 2009; 30: 212-217. PMid:20172633 http://dx.doi.org/10.1016/j.nedt.2009.12.012

[40] Bradbury-Jones C, Sambrook S, Irvine F. Empowerment and being valued: A phenomenological study of nursing students. Nurse Education Today. 2011; 31: 368-372. PMid:20696505 http://dx.doi.o $\mathrm{rg} / 10.1016 / \mathrm{j} . \mathrm{nedt} .2010 .07 .008$

[41] Nordin A, Wilde-Larsson B, Norström G, et al. Swedish hospital survey on patient safety culture - psychometric properties and health care staff's perceptions. Open Journal of Nursing. 2013a; 3: 41-50. http://dx.doi.org/10.4236/ojn.2013.38A006

[42] Nordin A, Theander K, Wilde-Larsson B, et al. Health care staff's perceptions of patient safety culture in hospital settings and factors of importance for this. Open Journal of Nursing. 2013b; 3: 28-40.

[43] Jerak-Zuioderent S. Certain uncertainties: Modes of patient safety in health care. Social Studies of Science. 2012; 42(5): 732-752. http://dx.doi.org/10.1177/0306312712448122

[44] White E, Winstanley J. Clinical supervision for nurses working in mental health settings in Queensland, Australia: selected findings from a novel Australian attempt to establish the evidence base for causal relationships with quality of care and patient outcomes, as an informed contribution to mental health nursing practice development. Journal of Research in Nursing. 2010; 15: 151-167. http://dx.doi.org/10.1177/1744987109357816

[45] Hyrkäs K, Appelqvist-Schmidlechner K, Haataja R. Efficacy of clinical supervision: influence on job satisfaction, burnout and quality of care. Journal of Advanced Nursing. 2006; 55: 52135. PMid:16866847 http://dx.doi.org/10.1111/j.1365-2 648.2006.03936.x

[46] Holm Wiebe A-K, Johansson I, Lindquist I. Severinsson E. Nurses' experiences of core phenomena in the supervisor training programme. In: Cutcliffe J, Hyrkas K, Fowler J, editors. Routledge Handbook of Clinical Supervision. Fundamental International Themes. New York; 2011; 241-249. 